Buana Sains Vol 17 No 2: 167 - 174, 2017

\title{
FAKTOR-FAKTOR YANG MENGHAMBAT PENDIDIKAN KARAKTER ANAK BURUH TANI DIKABUPATEN PONOROGO
}

\author{
Eri Yusnita Arvianti , Asnah, dan Anung Nugroho Prasetyo \\ Fakultas Pertanian Universitas Tribhuwana Tunggadewi Malang
}

\begin{abstract}
Character education is an education that teaches about the values of human behavior associated with the Almighty God, human beings, the environment, and nationality were manifest in mind attitudes, feelings, words, and actions based on religious norms, legal norms, manners, culture, and customs. This study aims to determine the obstacles of character education and the influences of character education to children in the family farm laborers to consistency in the agricultural sector. This research was conducted in the Sukosari Village and Mojorejo Village in Ponorogo Districit from April until November 2016.

The approach used in this research is quantitative and qualitative approaches. The results showed that the obstacle of parents in teaching children of farming is capital in an attempt to develop farming. Furthermore, the results of multiple regression analysis is the regression equation $\mathrm{Y}=1.733+0.785 \mathrm{X} 1-0.208 \mathrm{X} 2+0.622 \mathrm{X} 3+\varepsilon$. Hypothesis testing simultaneously explains that awareness of children, the child's feelings and actions in character education of children by parents significantly affect the consistency of child farm workers to pursue agriculture. Partial test showed awareness of children and children's actions significantly influence interest in farming in Ponorogo, while feeling effect is not significant.
\end{abstract}

Keywords: character education, family farmers, obstacles

\section{PENDAHULUAN}

Pendidikan karakter adalah sebuah usaha mendidik anak-anak agar dapat mengambil keputusan dengan bijak dan mempraktekkannya dalam kehidupan sehari-hari, sehingga mereka dapat memberikan kontribusi yang positif pada lingkungannya (Megawangi, 2004). Munculnya gagasan tentang pendidikan karakter cukup menarik perhatian berbagai kalangan masyarakat. Tidak dipungkiri bahwa pendidikan karakter memang sangat penting bagi bangsa Indonesia, terutama untuk mempersiapkan generasi muda sebagai calon pemimpin bangsa di masa yang akan datang.(Ahmadi, 2007).

Sebagai lembaga pendidikan yang pertama dan utama bagi anak, keluarga mempunyai peranan yang amat penting dan strategis dalam penyadaran, penanaman, dan pengembangan nilai moral sosial dan budaya. Sikap, kebiasaan, dan perilaku selalu dilihat, dinilai, dan ditiru oleh anaknya yang kemudian semua itu secara sadar atau tidak sadar diresapinya dan kemudian menjadi kebiasaan bagi anak-anaknya (Koesoema, 2010).

Hernanto (1989), buruh tani yang tidak memiliki tanah pertanian sama 
sekali atau yang hanya memiliki tanah pekarangan sajalah yang dinamakan buruh tani dalam pengertian yang sesungguhnya. Kurangnya perhatian badan pemerintah yang diberikan kepada kaum buruh tani baik secara langsung maupun tidak langsung atas nasib mereka kebanyakan buruh tani hidup dari hari ke hari dan tidak memperhatikan rencana masa depan. Sehingga banyak buruh tani yang beralih profesi dari sektor pertanian.

Peralihan kerja buruh tani ke sektor non pertanian,memiliki pengaruh terhadap cara pandang keluarga terutama anak yang ditinggalkan. Anak buruh tani kemudian lebih memilih menjadi TKI/ TKW di luar negeri seperti orangtuanya atau kebanyakan keluarga lainnya. Cara pandang yangdemikikan mengakibatkan terjadinya penurunan minat anak buruh tani pada dunia pertanian. Mereka terpacu menjadi buruh migran seperti orangtua mereka dan berharap mendapatkan penghasilan yang lebih tinggi dibandingkan bergelut di dunia pertanian.

Berdasarkan uraian di atas, maka permasalahan dalam penelitian ini yaitu penurunan minat anak buruh tani atau inkonsistensi anak buruh tani di sektor pertanian.

Adapun tujuan penelitian ini adalah: untuk mengetahui (1) bagaimana proses pelaksanaan pendidikan karakter dalam keluarga buruh tani di Kabupaten Ponorogo, (2) hambatan orang tua dalam memberikan pendidikan karakter pada anak, dan (3) faktor-faktor yang dapat mempengaruhi konsistensi anak buruh tani terhadap sektor pertanian.

\section{METODE PENELITIAN}

\section{Lokasi dan waktu penelitian}

Penelitian ini dilaksanakan di Kelurahan Mojorejo dan Kelurahan SukosariKabupaten Ponorogo yang mewakili daerah rural dan semi urban, dengan didasarkan atas pertimbangan bahwa: hasil penelitian terdahulu menunjukkan bahwa pemuda tani di kedua kelurahan tersebut cenderung lebih konsisten pada sektor pertanian karena memiliki penguasaan lahan yang luas $(>2.000 \mathrm{~m} 2)$, pendapatan tinggi $(>$ Rp. 15.000.000,00 per tahun), tidak memiliki keterampilan lain, dan status kependudukan yang merupakan penduduk asli. Penelitian ini dilaksanakan mulai tahun 2014 sampai dengan 2016.

\section{Metode Pengumpulan Data}

Data yang dikumpulkan dalam penelitian ini meliputi data primer dan data sekunder :

1. Data primer

a. Data yang diambil dari jawaban atas pertanyaan yang ditujukan kepada keluarga buruh tani di Desa Mojorejo dan Sukosari untuk memperoleh kejelasan dari data yang diambil.

b. Data/informasi dengan cara melakukan peninjauan secara langsung pada obyek penelitian.

2. Data sekunder yaitu data yang diperoleh dari daerah penelitian yang yaitu profil Desa Mojorejo dan Sukosari.

\section{Pendekatan Penelitian}

Penelitian ini menggunakan pendekatan kualitatif dan kuantitatif. Pendekatan kualitatif digunakan untuk mengetahui hambatan-hambatan orangtua dalam membentuk karakter anak. Pendekatan kuantitatif digunakan untuk menganalisis pengaruh aplikasi pendidikan karakter terutama mengetahui kesadaran, perasaan dan tindakan anak buruh tani terhadap konsistensi di sektor pertanian. 
E Yusnita, Asnah dan A. N. Prasetyo/Buana Sains Vol 17 No 2 : 167-174

\section{Metode Analisis Data}

Metode analisis data yang digunakan untuk menentukan dan mengalisis faktor-faktor yang mempengaruhi pilihan pekerjaan individu adalah analisa deskriptif statistic dan regresi linear berganda. Model regresi ini dianggap sebagai alat yang tepat untuk menganalisis data dalam penelitian ini karena variabel dependen dalam penelitian ini adalah pilihan pekerjaan yang bersifat dikotomi (Kuncoro, 2001). Berikut persamaan regresi yang digunakan dalam penelitian ini:

$\mathrm{Li}=\mathrm{KBSP}=\mathrm{BO}_{\mathrm{O}}+\beta 1 \mathrm{KSDR}+\beta 2$ PRSN + B3 TNDK+ e

Keterangan :

$\begin{array}{ll}\text { KBSP } & : \text { Konsistensi anak buruh } \\ & \text { tani di sektor pertanian } \\ \text { Bo } & : \text { Intercept } \\ \text { B1, .. B7 } & : \text { Koefisien regresi } \\ \text { KSDR } & : \text { Kesadaran } \\ \text { PRSN } & : \text { Perasaan } \\ \text { TNDK } & : \text { Tindakan }\end{array}$

\section{HASIL DAN PEMBAHASAN}

\section{Usia Anak Muda}

Tabel 1. Usia Anak Mulai Diajarkan

Bertani

\begin{tabular}{lcc}
\hline $\begin{array}{c}\text { Usia Anak } \\
\text { (Tahun) }\end{array}$ & Frekuensi & $\begin{array}{c}\text { Persen } \\
(\mathbf{\%})\end{array}$ \\
\hline$>14$ & 2 & 5 \\
$10-14$ & 1 & 2.5 \\
$5-9$ & 20 & 50 \\
$0-4$ & 17 & 42.5 \\
Total & 40 & 100 \\
\hline
\end{tabular}

Sumber: Data primer yang diolah

Penjelasan Tabel 1

menunjukkan bahwa $50 \%$ anak di Kelurahan Sukosari dan Kelurahan Mojorejo telah diajarkan oleh orangtua untuk bertani seperti; menanam padi, membajak sawah serta memberi pupuk pada tanaman padi pada usia 5-9 tahun, bahkan sebanyak 42,5\% anak telah diajarkan bertani pada usia 0-4 tahun. Hal ini menjelaskan bahwa masyarakat setempat telah memperkenalkan kegiatan bertani kepada anak-anaknya sejak usia dini.

a. Cara Mengajarkan Anak Bertani

Tabel 2. Cara Mengajarkan Anak Bertani

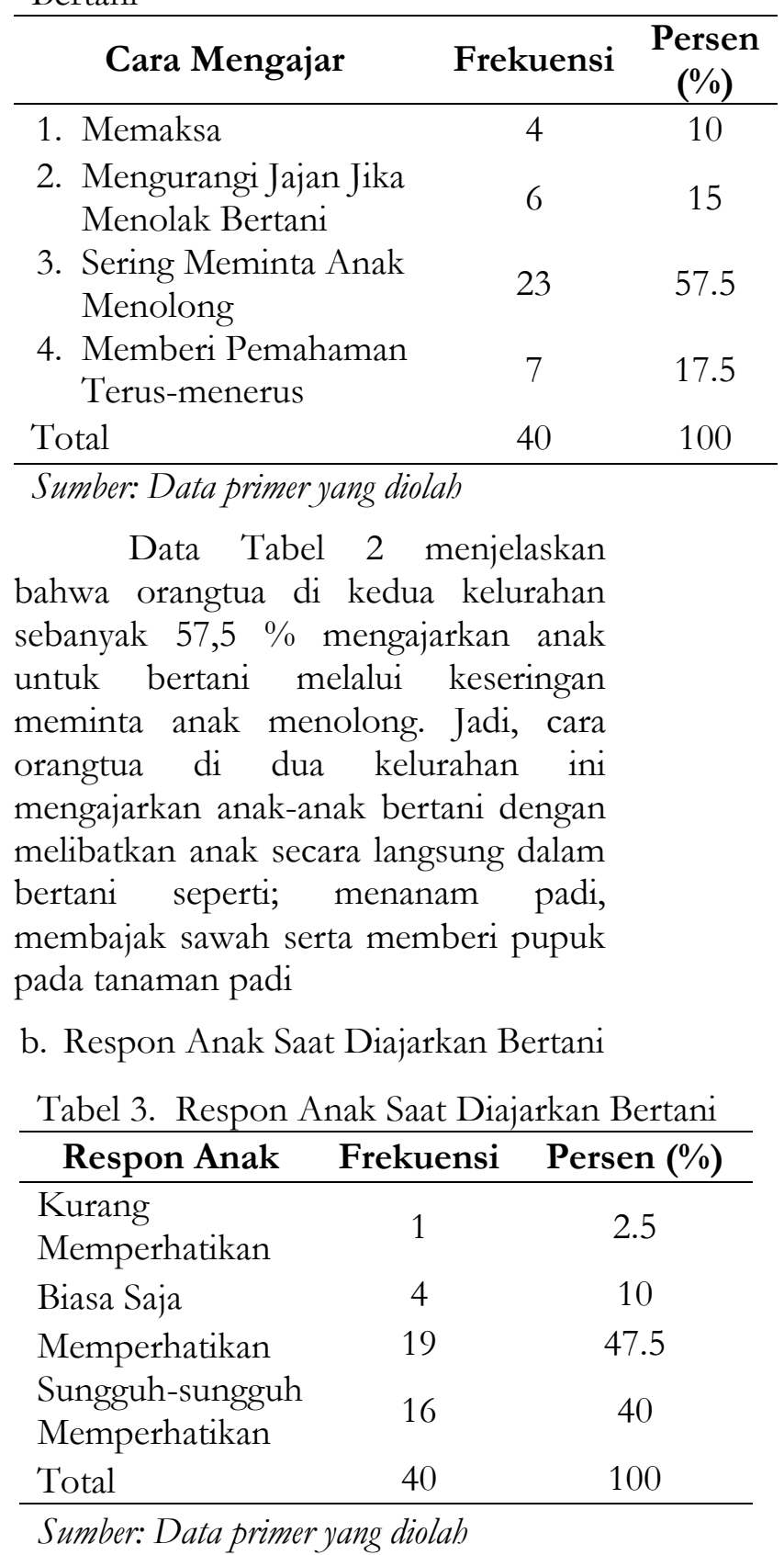


Tanggapan saat diajarkan bertani sebagaimana tampak pada Tabel 3, diketahui sebanyak 47,5\% anak memperhatikan. Dengan demikian diketahui ada antusias anak-anak di kedua kelurahan untuk mengenal dan mengetahui kegiatan bertani.

c. Partisipasi Anak Saat Persiapan Lahan

Tabel 4. Partisipasi Anak Saat

Persiapan Lahan

\begin{tabular}{lcc}
\hline $\begin{array}{c}\text { Partisipasi } \\
\text { Anak }\end{array}$ & Frekuensi & $\begin{array}{c}\text { Persen } \\
(\mathbf{\%})\end{array}$ \\
\hline Kadang- & 10 & 25 \\
kadang & 23 & 57.5 \\
Sering & 7 & 17.5 \\
Selalu & 40 & 100 \\
Total &
\end{tabular}

Sumber: Data primer yang diolah

Secara keseluruhan sebagaimana ditunjukkan Tabel 4, terdapat 57,5\% anak yang berpartisipasi pada saat orangtua mereka mempersiapkan lahan. $\mathrm{Hal}$ ini berarti sebagian besar anak terlibat dalam mempersiapkan lahan.

d. Partisipasi Anak Saat Penggemburan Tanah

Tabel 5. Partisipasi Anak Saat Penggemburan Tanah

\begin{tabular}{lcc}
\hline \multicolumn{1}{c}{ Partisipasi } & Frekuensi & $\begin{array}{c}\text { Persen } \\
(\mathbf{\%})\end{array}$ \\
\hline Kadang- & 7 & 17.5 \\
kadang & 20 & 50 \\
Sering & 11 & 27.5 \\
Selalu & 40 & 100 \\
Total & \multicolumn{2}{l}{}
\end{tabular}

Anak-anak yang ikut membantu orangtua untuk menggembur tanah sebanyak $50 \%$. e. Partisipasi Anak Saat Pemupukan

Tabel 6. Partisipasi Anak Saat

Pemupukan

\begin{tabular}{lcc}
\hline $\begin{array}{c}\text { Partisipasi } \\
\text { Anak }\end{array}$ & Frekuensi & $\begin{array}{c}\text { Persen } \\
(\mathbf{\%})\end{array}$ \\
\hline Kadang- & 2 & 17.5 \\
kadang & 22 & 55 \\
Sering & 11 & 27.5 \\
Selalu & 40 & 100 \\
Total & Sumber: Data primer yang diolah
\end{tabular}

Perlakuan terhadap tanaman berupa pemberian pupuk sering diikuti juga oleh $55 \%$ anak, sedangkan 27,5\% lainnya bahkan selalu berpartisipasi aktif saat pemupukan (Tabel 6). Hal ini menjelaskan bahwa sebagian besar anak-anak aktif membantu saat pemupukan.

f. Partisipasi Anak Saat Penyiangan

Tabel 7. Partisipasi Anak Saat

Penyiangan

\begin{tabular}{lcc}
\hline $\begin{array}{c}\text { Partisipasi } \\
\text { Anak }\end{array}$ & Frekuensi & $\begin{array}{c}\text { Persen } \\
(\mathbf{\%})\end{array}$ \\
\hline Tidak Pernah & 3 & 7.5 \\
Kadang- & 6 & 15 \\
kadang & 25 & 62.5 \\
Sering & 6 & 15 \\
Selalu & 40 & 100 \\
Total & \multicolumn{2}{c}{ Sumber: Data primer yang diolah }
\end{tabular}

Pada waktu pembersihan gulma pada Tabel 7, diketahui sebanyak 62,5 $\%$ anak sering membantu orangtua mereka dalam kegiatan pembersihan gulma dilahan. Hal ini menunjukkan bahwa sebagian besar anak-anak terlibat pada saat penyiangan. 
E Yusnita, Asnah dan A. N. Prasetyo/Buana Sains Vol 17 No 2 : 167-174

g. Partisipasi Anak Saat Pengairan

Tabel 8. Partisipasi Saat Pengairan

\begin{tabular}{lcc}
\hline $\begin{array}{c}\text { Partisipasi } \\
\text { Anak }\end{array}$ & Frekuensi & $\begin{array}{c}\text { Persen } \\
(\mathbf{0})\end{array}$ \\
\hline Tidak & 4 & 10 \\
Pernah & & \\
Kadang- & 8 & 20 \\
kadang & 23 & 57.5 \\
Sering & 5 & 12.5 \\
Selalu & 40 & 100 \\
Total & Sumber: Data primer yang diolah
\end{tabular}

Partisipasi anak saat pengairan sawah dapat dijelaskan pada Tabel 8, bahwa sebanyak 57,5\% anak sering membantu orangtua mereka. Secara keseluruhan diketahui bahwa sebagian besar anak berpartisipasi saat diadakan pengairan sawah.

h. Partisipasi Anak Saat Pengendalian Hama Dan Penyakit

Tabel 9. Partisipasi Anak Saat

Pengendalian Hama dan

Penyakit

\begin{tabular}{ccc}
\hline $\begin{array}{c}\text { Partisipasi } \\
\text { Anak }\end{array}$ & Frekuensi & $\begin{array}{c}\text { Persen } \\
(\%)\end{array}$ \\
\hline
\end{tabular}

\begin{tabular}{lcc}
\hline Tidak & 4 & 10 \\
Pernah & & \\
Kadang- & 5 & 12.5 \\
kadang & 18 & 45 \\
Sering & 13 & 32.5 \\
Selalu & 40 & 100 \\
Total & Sumber: Data primer yang & diolah
\end{tabular}

Data pada Tabel 9 menjelaskan bahwa pada saat pengendalian hama dan penyakit terdapat $45 \%$ anak yang sering terlibat dan 32,5\% anak yang selalu membantu orangtua. Dengan demikian menunjukkan bahwa hampir setengah dari anak buruh tani berpartisipasi dalam pengendalian hama dan penyakit. i. Partisipasi Anak Saat Panen

Tabel 10. Partisipasi Anak Saat

Panen

\begin{tabular}{lcc}
\hline $\begin{array}{c}\text { Partisipasi } \\
\text { Anak }\end{array}$ & Frekuensi & $\begin{array}{c}\text { Persen } \\
\mathbf{( \% )}\end{array}$ \\
\hline Kadang- & 8 & 20 \\
kadang & 23 & 57.5 \\
Sering & 9 & 22.5 \\
Selalu & 40 & 100 \\
Total & Sumber: Data primer yang diolah
\end{tabular}

Keterlibatan anak untuk ikut memanen produk pertanian yang telah mencapai umur kematangan dapat dijelaksan berdasarkan Tabel 10, dimana terdapat 57,5 \% anak yang sering membantu orangtua mereka. Hal ini berarti sebagian besar anak di kedua kelurahan sering berpartisipasi pada saat panen.

j. Partisipasi Anak Dalam Bertani Setiap Hari

Tabel 11. Partisipasi Anak Dalam Bertani Setiap Hari

\begin{tabular}{lcc}
\hline $\begin{array}{c}\text { Partisipasi } \\
\text { Anak }\end{array}$ & Frekuensi & $\begin{array}{c}\text { Persen } \\
\mathbf{( \% )}\end{array}$ \\
\hline 7-8 Jam & 1 & 2.5 \\
5-6 Jam & 7 & 17.5 \\
1-2 Jam & 23 & 57.5 \\
3-4 Jam & 9 & 22.5 \\
Total & 40 & 100 \\
\hline
\end{tabular}

Sumber: Data primer yang diolah

Data pada Tabel 11 menjelaskan tentang ragam alokasi waktu yang dihabiskan anak setiap hari untuk membantu orangtua dalam bertani.Dalam keseharian sebagian besar (57,5 \%) anak buruh tani menggunakan waktu 1-2 jam untuk bertani. 


\section{Hambatan Pendidikan Karakter dalam Keluarga Buruh Tani}

Faktor-faktor yang menghambat pendidikan karakter dalam keluarga buruh tani di Kelurahan Sukosari dan Kelurahan Mojorejo tidak begitu dirasakan oleh orang tua. Hal ini dipengaruhi oleh respon anak yang $60 \%$ menerima ajakaan untuk bertani.Sebagian besar anak merespon secara positif ajakan orang tua untuk bertani. Jikalau terjadi penolakan terhadap ajakan tersebut orang tua tidak memaksakan ataupun membiarkan, tetapi sebagian besar $(57,5 \%)$ orang tua justru memilih untuk mengarahkan anak dengan perlahan-lahan. Sikap ini lebih didasarkan pada proses penyadaran yang terusmenerus. Pengarahan berkelanjutan menjadi langkah konkret, desa tersebut mampu bertani, bahkan hampir setengahnya (30\%) sangat mampu dalam bertani. Selain itu, setengah (50\%) anak buruh tani di kedua kelurahan senang bertani, walaupun hampir setengahnya $(27,5 \%)$ tidak senang bertani.

Orang tua di kedua kelurahan justru mengeluhkan bahwa masalah utama yang dihadapi dalam mewariskan minat bertani pada anak-anak mereka adalah modal usahatani. Minimnya biaya mengakibatkan bidang usaha dalam pertanian tidak berkembang, serta hanya cukup untuk memenuhi kebutuhan hidup sehari-hari. Oleh karena itu, para orang tua meyakini apabila mereka memiliki modal mencukupi untuk melakukan seluruh proses produksi maka hal tersebut akan semakin menarik minat anak untuk menekuni pertanian, karena pertanian memang menjanjikan masa depan. Permasalahan modal diketahui juga menjadi penyebab anakanak semakin tidak berminat dalam bertani.
3. Model Pendidikan Karakter Anak Buruh Tani

Model pendidikan karakter anak buruh tani pada penelitian ini adalah sebagai berikut:

a. Metode Bercerita, Mendongeng (Telling Story); dengan bercerita atau mendongeng anak diperkenalkan karakter yang ada pada setiap tokoh dalam cerita. Model ini baik digunakan untuk semua umur, terlebih untuk anak-anak usia dini dan di Sekolah Dasar.

b. Model mangkuk ikan, model akuarium (fish bow'); peserta diskusi duduk setengah melingkar (pembicara) yang dipimpin oleh seorang moderator bertujuan untuk mengambil keputusan. Pengamat, akan berbicara kalau diberi kesempatan.

c. Metode Bembelajaran Kooperatif; biasa disebut kelompok pembelajaran. dimana ada saling berbagi, kerjasama dalam tim, mencapai tujuan bersama dalam suatu kondisi: saling ketergantungan positif, tanggung jawab individu, interaksi tatap muka, penerapan keterampilan kolaboratif dan proses kelompok.

4. Mengukur Pendidikan Karakter Bertani terhadap Konsistensi Anak Buruh Tani di Sektor Pertanian

a. Uji Asumsi Klasik

1) Uji Normalitas

Visualisasi Normal Probability

Plot pada hasil uji normalitas berdasarkan data residual, diketahui bahwa data observasi mengikuti garis diagonal, maka data tersebut dinyatakan normal.Pengujian nilai residual dengan menggunakan metode One Sample Kolmogorov-Smirnov(K-S) Test menunjukkan bahwa nilai K-S Z 0,549 dan nilai pobabilitas 
(signifikansi) 0,924 lebih besari dari pada taraf kesalahan $5 \%$ (nilai signifikansi 0,05). Hal ini berarti data residual berdistribusi normal, sehingga sebaran skor terhadap variabel Konsistensi Anak Buruh Tani di Sektor Pertanian, Variabel Kesadaran, Variabel Perasaan dan Variabel Tindakan berdistribusi normal.

2) Uji Multikolinearitas

Pengujian terhadap ada tidaknya korelasi antarvariabel bebas pada model regresi yang digunakan, menunjukkan bahwa nilai tolerance variabel Kesadaran adalah 0,524, variabel Perasaan 0,383 dan variabel Tindakan adalah 0,412 lebih besar dari (>) 0,1 atau mendekati 1. Nilai Variance Inflation Factor (VIF) untuk ketiga variabel tersebut masingmasing 1,909; 2,613; 2,430 atau berada di sekitar nilai kurang dari sepuluh.Hal ini menjelaskan bahwa tidak terjadi korelasi antarvariabel bebas atau tidak terjadi multikolinearitas.

3) Uji Heteroskedastisitas

Visualisasi pada scaterplot menunjukkan bahwa titik sebaran variasi residual data yang diamati berserakan.Hal ini menjelaskan bahwa tidak terjadi heteroskedastisitas pada model regresi yang digunakan, sehingga model regresi layak digunakan untuk memprediksi Konsistensi Anak Buruh Tani di Sektor Pertanian.

b. Analisa Regresi Linear Berganda

Perolehan hasil analisa regresi berganda adalah suatu persamaan regresi sebagai berikut:

$\mathrm{Y}=1,733+0.785 \mathrm{X} 1-0.208 \mathrm{X} 2+$ $0.622 \mathrm{X} 3+\varepsilon$

Interpretasi model regresi tersebut adalah sebagai berikut:

1) $\beta 0=1,733$. Koefisien regresi ini menunjukkan bahwa tanpa adanya pegaruh dari variabel-variabel bebas terhadap variabel $\mathrm{Y}$ (Konsistensi Anak Buruh Tani di Sektor Pertanian), maka nilai dari variabel $\mathrm{Y}$ sudah meningkat sebesar 1,733 .

2) $\beta 1=0.785$. Jika terjadi peningkatan Kesadaran (X1) sebesar 1 skala jawaban dan variabel bebas lain tetap, maka terjadi peningkatan skor Konsistensi Anak Buruh Tani di Sektor Pertanian (Y) sebesar 0,785. Dapat dilihat bahwa koefisien yang diperoleh bernilai positif, jadi Kesadaran (X1) meningkat, minat Konsistensi Anak Buruh Tani di Sektor Pertanian (Y) meningkat juga, dan sebaliknya.

3) $\beta 2=-208$. Jika terjadi peningkatan Perasaan (X2) sebesar 1 skala jawaban dan variabel bebas lain tetap, maka terjadi penurunan skor Konsistensi Anak Buruh Tani di Sektor Pertanian (Y) sebesar 0,208. Dapat dilihat bahwa koefisien yang diperoleh bernilai negative.

4) $\beta 3=0.622$ Jika terjadi peningkatan Tindakan (X3) sebesar 1 skala jawaban dan variabel bebas lain tetap, maka terjadi peningkatan skor Konsistensi Anak Buruh Tani di Sektor Pertanian (Y) sebesar 0.622. Dapat dilihat bahwa koefisien yang diperoleh bernilai positif.

\section{KESIMPULAN}

Secara keseluruhan penelitian ini menghasilkan beberapa kesimpulan sebagai berikut:

1. Proses pelaksanaan pendidikan karakter untuk bertani di Kelurahan Sukosari dan Mojorejo telah dimulai sejak usia dini dengan cara melibatkan anak dalam bertani. Anak memiliki antusias dan berpartisipasi 
2. secara langsung pada proses budidaya sampai dengan panen.

3. Hambatan utama orang tua dalam pendidikan karakter bertani adalah modal. Orang tua meyakini modal yang cukup untuk usahatani akan semakin meningkatkan minat anak unuk menekuni pertanian.

4. Dari hasil regresi berganda uji secara simultan, kesadaran anak, perasaan anak dan tindakan anak dalam pendidikan karakter oleh orang tua berpengaruh secara nyata terhadap konsistensi anak buruh tani untuk menekuni pertanian di Kabupaten Ponorogo.

5. Berdasarkan uji parsial kesadaran anak dan tindakan anak berpengaruh secara signifikan terhadap minat bertani.

\section{Daftar Pustaka}

Ahmadi, Abu. 2007. Sosiologi Pendidikan. Jakarta: Rineka Cipta.

Hernanto, F. 1989. Ilmu Usaha Tani. Penerbit Swadaya. Jakarta.

Koesoema, Doni. 2010. Pendidikan Karakter: Strategi Membidik Anak di Jaman

Global. Jakarta: Grasindo.

Kuncoro, Mudrajad. 2001. "Metode Kuantitatif: Teori dan Aplikasi untuk Bisnis dan Ekonomi". Yogyakarta: UPP-AMPP YKPN.

Megawangi, Ratna. 2004. Pendidikan Karakter Solusi yang Tepat untuk Membangun

Bangsa. Jakarta: BPMGAS. 